\title{
Do English Language Teachers' Characteristics Affect Self-Efficacy?
}

\author{
Margaretha Dharmayanti Harmanto ${ }^{1, *}$ Amalia Savitri Adi ${ }^{2}$
}

\author{
${ }^{1}$ Universitas Muhammadiyah Yogyakarta \\ ${ }^{2}$ Universitas Muhammadiyah Yogyakarta \\ *Corresponding author. Email: margaretha@umy.ac.id
}

\begin{abstract}
This study aims to investigate the effect of English Language teachers' characteristics on their self-efficacy. The teachers' characteristics in this study referred to gender, length of teaching (in years), academic qualification, teaching institution, kinds of English subject taught (EGP or ESP), and province where the respondents taught. The method used in this study was a quantitative study. The data were obtained from 84 English teachers in Indonesia using the teachers' self-efficacy questionnaire. There were five factors of English teachers' self-efficacy in this study: self-efficacy in teaching knowledge, teaching ethic, classroom management, instructional strategies, and student engagement. The study data were analysed, employing multilinear regression. This study revealed that gender, teaching experience, academic qualification institution, kinds of English subject taught, and province where the teachers taught simultaneously did not affect teachers' self-efficacy with $0.793,0.932,0.114,0.395,0.436$, and 0.223 , respectively.
\end{abstract}

Keywords: teachers' characteristics, self-efficacy

\section{INTRODUCTION}

The teacher is one of the essential keys to the teaching-learning process. Teachers' self-efficacy is part of the motivation issue, and it is one of the aspects that shape the teachers' profession, investment in their professional development, and classroom exercise [1]. However, Klassen, Durksen, and Tze (2014) stated that there had been only a few research on teachers' selfefficacy related to real practices or policies. One of the reasons is concerning the sources that affect teachers' self-efficacy [1]. Besides, a keen awareness of efficacy will increase self-achievement and individual well-being in various ways [2]. Teachers' characteristics influence teachers' attitudes, nature, purpose setting, achievement, and failure [3]. It has been empirically proved that teachers' factors positively impacted teachers' selfefficacy and job satisfaction when teaching students with disabilities [3].

According to Wolters \& Daugherty (2007), teaching level and gender significantly affected elementary teachers' self-efficacy compared to middle or high school level teachers [4]. They focused on the relationship between teachers' self-efficacy and their teaching experience. Their study uncovered that teaching experience had only a moderate effect on teachers' self- efficacy. However, little attention is paid to whether teachers' characteristics impact teachers' self-efficacy, particularly in Teaching English as a Foreign Language (TEFL). Therefore, this study aims to investigate the effect of English Language teachers' characteristics on their self-efficacy.

\section{LITERATURE REVIEW}

\subsection{Self-Efficacy}

Self-efficacy is defined as "beliefs in one's capabilities to organise and execute the courses of action required to produce given attainments" [5]-[7]. He further stated that self-efficacy beliefs control the way people feel, think, motivate themselves, and behave [2]. A keen awareness of efficacy will increase selfachievement and individual well-being in various ways [2]. According to Tschannen-moran et al. (1998), selfefficacy refers to the perception of self-competence rather than actual competence [8]. "The efficacy belief system is not a universal attribute but a distinct collection of self-beliefs connected to different operating realms" [7]. When people do not have self-efficacy, they will not strive for their efforts since they think their actions are pointless [9]. 


\subsubsection{Teachers' Self-efficacy}

The concept of teacher self-efficacy itself was first born from RAND researchers, based on Rotter's theory (1976) [8]. They investigated to what extent teachers believed that they could manage the reinforcement of their actions, in this case, whether the control of support was from the teachers or came from the environment [8]. Bandura (1977) introduced the second concept that considered teacher self-efficacy as the category of selfefficacy [8]. Teacher self-efficacy is defined by Berman et al. (1977) as "the level at which teachers believe that they can influence their students' performance" [8], [10]. Besides, Gaskey and Passaro (1994) define teacherefficacy as "teachers' belief that they can influence their students to learn better even for those who are difficult or unmotivated" [9]. Further elaboration on teacher efficacy is "the teacher's belief in his or her capability to organise and execute courses of action required to accomplish a specific teaching task in a particular context" [8]. Teachers' self-efficacy is also defined as "their beliefs in their abilities to support learning in the various task and context-specific cognitive, metacognitive, affective, and social ways" [11].

The study of teachers' self-efficacy embarks to different variables, among others are learning subjects [12], [13], sources of teachers' self-efficacy [9], [14], teachers in pre-service, pre-school, and primary schools [15], [16], and lesson study, school culture, and condition [17]. Besides that, some studies also investigated the effect of teachers' self-efficacy on the teachers' feeling of burn out [18]; interpersonal role identity, burn out, and work engagement [19]; job satisfaction [20]; personality and teaching performance [21].

Several studies were also conducted on teachers' characteristics affecting self-efficacy, such as the study by [3], which investigated the effect of teaching students with disabilities, as well as by [4], which associated teachers' self-efficacy with teaching experience and academic level. The differences in teachers' self-efficacy can be affected by academic qualifications. For example, the type and scope of teachers' training, the organisation and atmosphere of schools, and the changes growthrelated among students may impact teachers' selfefficacy [4]

In measuring teachers' self-efficacy, some instruments have been developed; one is the Teachers' Sense of Efficacy Scale/TSES [22]. This instrument elaborates on three aspects: student engagement, instructional strategies, and classroom management [22]. This instrument has been developed in correlation to other variables, for instance, teachers' self-efficacy belief for reading instruction [9], learner autonomy support behaviour [23], and teacher interaction and job satisfaction [20]. Further, Rezvani \& Amiri (2013) created instruments developed from the TSES to investigate the English language teachers' self-efficacy
[24]. This instrument added demographic data such as gender, teaching experience, educational level, and field of study, divided into teaching, translation, and teaching. In this study, teachers' characteristics included gender, teaching experience or length of education, academic qualification, and teaching subject, divided into English for General Purposes (EGP) and English for Specific Purposes (ESP). This study also added the institutions where the teachers taught and the province where they taught.

This study hypothesises that English language teachers' characteristics have a significant effect on teachers' self-efficacy belief.

\section{METHODOLOGY}

A quantitative survey-type descriptive study was utilised for an experiential group of data and analyses. The data sampling was gathered using purposive sampling, in which the sample was selected based on the consideration and specific criteria determined by the researchers. This study employed a survey technique to investigate the teachers' self-efficacy. The instrument used was a questionnaire adapted from a questionnaire of English Language teachers' self-efficacy [24]. The questionnaire consisted of two elements: the English Language teachers' self-efficacy and the demographic data represented the teachers' characteristics. As many as 84 English teachers in Indonesia participated in this study.

The data gathered were analysed using SPSS 22. This study's dependent variable was the self-efficacy valued through the teaching knowledge and teaching ethics, classroom management, teaching instruction, and students' involvement. Every section was measured by scaling between one to six; the higher the scale was the higher the respondent's ability. Meanwhile, this study's independent variables were gender, length of teaching, educational background and educational institution, and the English subject (EGP or ESP). This study used the Multiple Regression Analysis to see the effect of dependent and independent variables.

\section{RESULTS AND DISCUSSION}

The teacher participants were recruited through a convenience sample of 84 , including $79,8 \%$ women $(\mathrm{n}=$ $67)$ and $20,2 \%$ men $(n=17)$ from five kinds of educational institutions: senior high school, vocational high school, higher education institute, English language school, and elementary school. Based on the academic qualifications, most of the respondents were teachers with a master's degree $(n=44)$, while the rest was a bachelor's degree $(n=40)$. The participants were grouped into four categories of teaching year experience: (1) less than one year, (2) 2 to 5 years, (3) 6 to 10 years, (4) 11 to 20 years, and (5) more than 20 years. The majority of teachers had 11 to 20 years of teaching experience $(n=$ 
34), 26 respondents had 6 to 10 years of teaching experience, 16 respondents had 2 to 5 years of teaching experience, and the rest had more than 20 years of teaching experience $(n=8)$. There were two teaching subjects used as options in this study: (1) English for

General Purposes $(\mathrm{n}=37)$ and (2) English for Specific Purposes $(n=47)$. The provinces where the participants taught mostly were in Java Island, including Yogyakarta $(n=64)$, Central Java $(n=16)$, Banten $(n=3)$, and Jakarta $(n=1)$. One participant was from Riau, and one participant did not mention the province.

\subsection{Results}

\subsubsection{Determining how well the model fit}

The first table shows the model summary (Table 1). This table displays the $\mathrm{R}, \mathrm{R} 2$, adjusted $\mathrm{R} 2$, and the estimate standard error. It provides information to decide how well a regression model fits the data [25].

The "R" column symbolised the value of $R$, the multiple correlation coefficient. $\mathrm{R}$ could be considered one measure of the quality in predicting the dependent variable, namely self-efficacy. A value of .059 indicated the prediction level. The "R Square" column represented the $R^{2}$ value or the coefficient of determination. It revealed the proportion of variance in the dependent variable described by the independent variables [25]. The Adjusted R Square value of 0.059 signified that the independent variables (gender, teaching experience, academic qualification, subjects, educational institutions, and provinces) only explained the dependent variable by $5.9 \%$. In contrast, $94.1 \%$ were explained by other factors not included in the model.

Table 1. Model Summary

\begin{tabular}{|l|l|l|l|l|}
\hline \multirow{2}{*}{ Model } & $\mathrm{R}$ & $\mathrm{R}$ Square & $\begin{array}{l}\text { Adjusted R } \\
\text { Square }\end{array}$ & $\begin{array}{l}\text { Std. Error of } \\
\text { the Estimate }\end{array}$ \\
\hline 1 &, $243^{\mathrm{a}}$ &, 059 &,- 014 &, 58415 \\
\hline
\end{tabular}

a. Predictors: (Constant), gender, teaching experience, academic qualification, subject taught, institution, and province.

b. Dependent Variable: Self Efficacy

\subsubsection{Statistical significance of the model}

The F-ratio in the ANOVA (Table 2) tests whether the overall regression model is a good fit for the data. The table reveals that statistically, the independent variables did not significantly predict the dependent variable with $\mathrm{F}(6,77)=0.803, \mathrm{p}(.571)>.05$.

Table 2 exhibits the value of F-count $0,803<\mathrm{F}$ table 3.05; thus, the hypothesis was rejected. It denoted that simultaneously, the independent variables (gender, length of teaching, academic qualifications, subjects, educational institutions, and provinces) did not significantly affect self-efficacy.

Table 2. ANOVA

\begin{tabular}{|cl|c|c|c|c|c|}
\hline \multirow{2}{*}{ Model } & $\begin{array}{c}\text { Sum of } \\
\text { Squares }\end{array}$ & df & $\begin{array}{c}\text { Mean } \\
\text { Square }\end{array}$ & F & Sig. \\
\hline 1 & Regression & 1,644 & 6 &, 274 &, 803 &, $571^{\mathrm{b}}$ \\
& Residual & 26,275 & 77 &, 341 & & \\
Total & 27,918 & 83 & & & \\
\hline
\end{tabular}

a. Dependent Variable: Self Efficacy

b. Predictors: (Constant) gender, teaching experience, academic qualification, subject taught, institution, and province.

\subsubsection{Statistical significance of the independent variables}

The significance of the independent variable's effect on the dependent variable can be seen from the Sig. Column. The significance value for each variable was $0.793,0.932,0.114,0.395,0.436$, and 0.223 on gender, teaching experience, academic qualification, subject taught, institution, and province, respectively. Each variable's significance value was higher than $P 0.05$, meaning that simultaneously, the independent variables did not affect self-efficacy.

\subsection{Discussion}

This study investigated the effect of teachers' characteristics on self-efficacy beliefs. This study's teachers' attributes included gender, teaching experience, academic qualification, subject taught, institution, and province. This study's results revealed that gender did not significantly affect teachers' self-efficacy beliefs (Table $3)$. It is different from the study results by Alwaleedi (2016) and Shaukat et al. (2013, 2019), which confirmed that gender had a significant effect on teachers' selfefficacy [3], [26], [27]. Alwaleedi (2016) indicated that there was considerable variance between male and female teachers related to teaching children with disabilities. The research conducted by Alwaleedi (2016) also confirmed that gender significantly impacted teachers' self-efficacy, including classroom management, persistent behaviour, classroom anxiety, and professional mastery [3]. It is similar to the study results by Sikandar (2017), which indicated that in terms of instructional strategies, student engagement, and classroom management, female teachers showed better and higher self-efficacy[28]. On the other hand, this study indicated that gender did not affect the English teachers' selfefficacy, including teaching knowledge, teaching ethics, classroom management, instructional strategies, and student engagement. 
Table 3. Coefficients

\begin{tabular}{|ll|c|c|c|c|c|c|c|}
\hline \multirow{2}{*}{ Model } & \multicolumn{2}{|c|}{$\begin{array}{c}\text { Unstandardized } \\
\text { Coefficients }\end{array}$} & $\begin{array}{c}\text { Standardized } \\
\text { Coefficients }\end{array}$ & & \multicolumn{3}{|c|}{$\begin{array}{c}\text { Collinearity } \\
\text { Statistics }\end{array}$} \\
\cline { 2 - 7 } & B & Std. Error & Beta & $\mathrm{t}$ & Sig. & Tolerance & VIF \\
\hline 1 (Constant) & 4,423 &, 589 & & 7.506 &, 000 & & \\
Gender &, 043 &, 162 &, 030 &, 263 &, 793 &, 962 & 1,039 \\
Teaching experience &,- 006 &, 074 &,- 010 &,- 085 &, 932 &, 914 & 1,095 \\
Education qualification &, 224 &, 140 &, 194 & 1,600 &, 114 &, 829 & 1,206 \\
Institution &,- 089 &, 103 &,- 109 &,- 856 &, 395 &, 747 & 1,339 \\
Teaching subject &, 109 &, 139 &, 094 &, 784 &, 436 &, 856 & 1,168 \\
Province &, 094 &, 077 &, 140 & 1,227 &, 223 &, 942 & 1,062 \\
\hline
\end{tabular}

a. Dependent Variable: Self Efficacy

The study conducted by Sikandar (2017) disclosed that teachers with a higher academic qualification level had more self-efficacy than teachers with a lower degree of academic qualification [28]. Alwaleedi (2016) also indicated that the educational background, such as BA, $\mathrm{MA}$, and $\mathrm{PhD}$, had a significant effect on teachers' selfefficacy among teachers in Saudi Arabia [26]. However, most of the study participants held master's degrees, and the rest had bachelor's degrees. The study results showed that their academic backgrounds did not affect their selfefficacy level with the significance value calculated of 0.114 .

Besides, the English subject that the participants taught was categorised into two: English for General Purposes (EGP) and English for Specific Purposes (ESP). This study revealed that the English subjects the teachers taught did not have a significant effect on the teachers' self-efficacy. It implied that whether they taught English for general purposes or specific purposes, it did not affect their self-confidence in teaching English.

Wolters and Daugherty (2007) also revealed that gender, teaching level, and teaching experience significantly impacted elementary teachers' self-efficacy compared to middle or high school level teachers [4]. However, this study exhibited that different teaching levels, represented by the institution variable, such as senior high school, vocational high school, higher education institute, English language course, and elementary school, had no significant effect on teachers' self-efficacy beliefs among English language teachers in Indonesia.

The last part of the demographic features in this study was the province. Indonesia consists of 34 provinces that spread along the peninsula. Each region has different geographical and ethnic characters, influencing the teaching-learning process when teaching English as a Foreign Language. Nevertheless, the study's results exposed the significance value of 0.223 , which was higher than 0.05 ; it indicated that different provinces did not affect the teachers' self-efficacy in teaching English.

\section{CONCLUSION}

Five factors of English teachers' self-efficacy in this study are self-efficacy in teaching knowledge, teaching ethic, classroom management, instructional strategies, and student engagement. However, the study results showed that teachers' characteristics did not significantly affect the teachers' self-efficacy. Since there were no significant effects on teachers' characteristics, it could be concluded that other factors influenced teachers' selfefficacy. Therefore, further study needs to be conducted to find out the factors contributing to self-efficacy.

\section{IMPLICATIONS AND FURTHER STUDY}

The study results have implications that factors contributing to self-efficacy need to be studied further. The qualitative method can be used to reveal the factors that may contribute to English language self-efficacy. Since other studies were conducted outside Indonesia and specifically investigate English teachers, future research needs to explore further issues, and self-efficacy such as job satisfaction burn out and their impact on students' performance in studying English.

Knowing the factors that contribute to teachers' selfefficacy can enrich the study on self-efficacy and eliminate factors that hinder self-efficacy, such as burn out. The study results on teachers' self-efficacy issues can provide insight into teachers' professional development or other educational policies.

\section{AUTHORS' CONTRIBUTIONS}

MDH wrote the manuscript and analysed the data. ASA calculated the statistical data.

\section{ACKNOWLEDGMENTS}

This study is part of the research grant provided by Universitas Muhammadiyah Yogyakarta. The authors would like to thank Research, Publication and Community Development Institute (LP3M) Universitas Muhammadiyah Yogyakarta for the opportunity of 
conducting this study. We give our gratitude to all participants who have contributed to this study.

\section{REFERENCES}

[1] M. Kubanyiova, "Language Teacher Motivation Research: Its Ends, Means and Future Commitments," in The Palgrave Handbook of Motivation for Language Learning, M. Lamb, K. Csizer, H. Alastair, and S. Ryan, Eds. Cham: Palgrave Macmillan, 2019, pp. 389-407.

[2] A. Bandura, "Self-Efficacy," in Encyclopedia of human behavior, vol. 4, no. 1994, V. S. Ramachaudran, Ed. New York: Academic Press, 1994, pp. 71-81.

[3] S. Shaukat, V. R. Vishnumolakala, and G. Al Bustami, "The impact of teachers' characteristics on their self-efficacy and job satisfaction: a perspective from teachers engaging students with disabilities," J. Res. Spec. Educ. Needs, vol. 19, no. 1, pp. 68-76, 2019, doi: 10.1111/1471-3802.12425.

[4] C. A. Wolters and S. G. Daugherty, "Goal structures and teachers' sense of efficacy: Their relation and association to teaching experience and academic level," J. Educ. Psychol., vol. 99, no. 1, pp. 181-193, 2007, doi: 10.1037/00220663.99.1.181.

[5] A. Bandura, Albert Bandura - Self-Efficacy_ The Exercise of Control. New York: W. H. Freeman and Company, 1997.

[6] A. Bandura, "Self-efficacy: Toward a Unifying Theory of Behavioral Change," vol. 84, no. 2, pp. 191-215, 1977.

[7] A. Bandura, "Guide for Constructing SelfEfficacy Scales," in Self-Efficacy Beliefs of Adolescents, Vol. 5., F. Pajares and T. Urdan, Eds. Greenwich, CT: Information Age Publishing, 2006, pp. 307-337.

[8] M. Tschannen-moran, A. W. Hoy, and W. K. Hoy, "Teacher Efficacy: Its meaning and Measure," Rev. Educ. Res., vol. 68, no. 2, pp. 202-248, 1998, doi: $10.3102 / 00346543068002202$.

[9] M. Tschannen-moran and P. Mcmaster, "Sources of Self-Efficacy : Four Professional Development Formats and Their Relationship to Self-Efficacy and Implementation of a New Teaching Strategy," vol. 110, no. 2, pp. 228245, 2009.
[10] M. Mo, C. Mok, and P. J. Moore, "Teachers \& self-efficacy," Educ. Psychol., vol. 39, no. 1, pp. 1-3, 2019, doi: 10.1080/01443410.2019.1567070.

[11] M. Wyatt, “An English teacher's developing self-efficacy beliefs in using groupwork," System, vol. 38, no. 4, pp. 603-613, 2010, doi: 10.1016/j.system.2010.09.012.

[12] A. A. Arigbabu, D. I. Oludipe, A. A. Arigbabu, and D. I. Oludipe, "Perceived Efficacy Beliefs of Prospective Nigerian Science Teachers," vol. 19, no. 1, pp. 27-31, 2019, doi: 10.1007/s.

[13] L. A. Pruski et al., "Construct Validation of the Self-Efficacy Teaching and Knowledge Instrument for Science Teachers- Revised ( SETAKIST-R ): Lessons Learned," vol. 1847, 2017, doi: 10.1007/s10972-013-9351-2.

[14] E. Cornelia, M. Van Rooij, M. Fokkensbruinsma, and M. Goedhart, "Preparing Science Undergraduates for a Teaching Career : Sources of Their Teacher Self-Efficacy Preparing Science Undergraduates for a Teaching Career : Sources of Their Teacher Self-Efficacy," Teach. Educ., vol. 54, no. 3, pp. 270-294, 2019, doi: 10.1080/08878730.2019.1606374.

[15] S. Walan and S. C. Rundgren, "Investigating Preschool and Primary School Teachers' SelfEfficacy and Needs in Teaching Science: A Pilot Study," CEPS J., vol. 4, no. 1, pp. 51-67, 2014.

[16] L. Hamilton, "Early Professional Development in the Scottish context : Pre-service High School Teachers and the Management of Behaviour in Classrooms," vol. 4530, no. February, 2016, doi: 10.1080/13664530.2015.1032338.

[17] T. M. Schipper, S. de Vries, S. L. Goei, and K. van Veen, "Promoting a professional school culture through lesson study? An examination of school culture, school conditions, and teacher self-efficacy," Prof. Dev. Educ., vol. 00, no. 00, pp. 1-18, 2019, doi:

10.1080/19415257.2019.1634627.

[18] W. P. Oakes, K. L. Lane, and A. Jenkins, "Three-Tiered Models of Prevention: Teacher Efficacy and Burnout Author ( s ): Wendy Peia 
Oakes, Kathleen Lynne Lane, Abbie Jenkins and Belle B . Booker Published by: West Virginia University Press Stable URL : https://www.jstor.org/stable/42900228 Thr," vol. 36, no. 4, pp. 95-126, 2019.

[19] A. C. van der Want, P. den Brok, D. Beijaard, M. Brekelmans, L. C. A. Claessens, and H. J. M. Pennings, "The relation between teachers' interpersonal role identity and their selfefficacy, burnout and work engagement," Prof. Dev. Educ., vol. 45, no. 3, pp. 488-504, 2019, doi: $10.1080 / 19415257.2018 .1511453$.

[20] I. Veldman, W. Admiraal, J. van Tartwijk, T. Mainhard, and T. Wubbels, "Veteran teachers' job satisfaction as a function of personal demands and resources in the relationships with their students," Teach. Teach. Theory Pract., vol. 22, no. 8, pp. 913-926, 2016, doi: 10.1080/13540602.2016.1200546.

[21] M. N. R. Hadjam and W. Widhiarso, "Efikasi mengajar sebagai mediator peranan faktor kepribadian terhadap performasi mengajar guru," Humanitas (Monterey. N. L)., vol. VII, no. 1, pp. 1-16, 2011.

[22] M. Tschannen-Moran and A. W. Hoy, "Teachers' Sense of Efficacy Scale Instrument," Teach. Teach. Educ., vol. 17, no. 1, pp. 783805, 2001.
[23] N. Ozkal, "Sense of professional self-efficacy beliefs and learner autonomy support behaviour of middle school teachers," Anthropologist, vol. 18 , no. 2 , pp. 575-581, 2014, doi: 10.1080/09720073.2014.11891575.

[24] R. Rezvani and T. Amiri, "English language teachers' efficacy beliefs: Validation of the instrument," Int. J. Appl. Linguist. English Lit., vol. 2, no. 4, pp. 14-26, 2013, doi:

10.7575/aiac.ijalel.v.2n.4p.14.

[25] Chuda Dhakal, "Interpreting the basic outputs (SPSS) of multiple linear regression," Int. J. Sci. Res., no. June, pp. 4-9, 2018, doi: 10.21275/4061901.

[26] M. A. Alwaleedi, "Impact of Demographic Variables in the Development of Teachers' SelfEfficacy Beliefs in the Context of Saudi Arabia," Asian Soc. Sci., vol. 13, no. 1, p. 1, 2016, doi: 10.5539/ass.v13n1p1.

[27] S. Shaukat, U. Sharma, and B. Furlonger, "Pakistani and Australian Pre-Service Teachers' Attitudes and Self-Efficacy towards Inclusive Education," J. Behav. Sci., vol. 23, no. 2, pp. 116, 2013.

[28] A. Sikandar, "Impact of Teacher Self-Efficacy on Secondary School Students' Academic Achievement," J. Educ. Educ. Dev., vol. 4, no. 1, pp. 32-47, 2017. 